\title{
Mixed Blessing: The Beneficial and Detrimental Effects of Religion on Child Development among Third-Graders
}

\author{
John P. Bartkowski ${ }^{1, *\left(\mathbb{D}, \text { Xiaohe } \mathrm{Xu}^{1,2} \text { (1) and Stephen Bartkowski }\right.}{ }^{3}$ \\ 1 Department of Sociology, University of Texas at San Antonio, San Antonio, TX 78249, USA; \\ xiaohe.xu@utsa.edu \\ 2 The School of Public Administration, Sichuan University, Chengdu 610064, China \\ 3 Institutional Research and Effectiveness Services, Alamo Colleges District, 201 W. Sheridan, San Antonio, \\ TX 78204, USA; stephenbartkowski@gmail.com \\ * Correspondence: john.bartkowski@utsa.edu
}

Received: 9 November 2018; Accepted: 4 January 2019; Published: 9 January 2019

\begin{abstract}
Previous research has linked parental religiosity to a number of positive developmental characteristics in young children. This study introduces the concept of selective sanctification as a refinement to existing theory and, in doing so, adds to a small but growing body of longitudinal research on this topic. We explore how parents' religious attendance (for fathers, mothers, and couples) and the household religious environment (parent-child religious discussions, spousal conflicts over religion) influence child development among third-graders. Analyses of longitudinal data from the Early Childhood Longitudinal Study (ECLS)-Kindergarten Cohort reveal a mix of salutary (beneficial) and adverse (detrimental) developmental outcomes based on teachers' ratings and standardized test performance scores. Third-graders' psychological adjustment and social competence are enhanced by various religious factors, but students' performance on reading, math, and science tests is hampered by several forms of parental religiosity. We discuss the implications of these findings and suggest several avenues for future research.
\end{abstract}

Keywords: religion; faith; spirituality; child development; youth; standardized test

\section{Introduction}

In the last several years, a great deal of attention has been paid to the role of religion in socializing young people (among recent studies, see Chiswick and Mirtcheva 2013; Petts 2011a, 2011b, 2012; Petts and Kysar-Moon 2012; for reviews, see Bartkowski 2007; Hemming and Madge 2011; Holden and Williamson 2014; Nelson 2009). While the bulk of early research had detected the beneficial effects of religion on adolescent dispositions and behaviors (e.g., Smith and Denton 2005), increasing attention is now being given to religion's influence on the development of elementary and middle school-age children (e.g., Bartkowski et al. 2008; Chiswick and Mirtcheva 2013; Miller et al. 1997; Petts 2012; Petts and Kysar-Moon 2012). One of the earliest studies to use national data revealed that parental religiosity, especially the frequency of couples' worship service attendance, was associated with enhanced psychological adjustment and social competence among primary school-age children (Bartkowski et al. 2008). Religious solidarity among couples and parent-child communication about religion were also linked with positive developmental characteristics, while religious conflict among spouses either failed to yield salutary effects or was connected to adverse outcomes. More recent inquiries have revealed that parental religiosity can have beneficial effects on child development even under challenging circumstances, such as within single-mother households (Petts 2012) and among 
disadvantaged fathers in urban areas (Petts 2011b). In short, religion can be a vital part of a children's developmental foundation.

To date, a handful of studies have used longitudinal data to examine the effects of religion on child development and have revealed a number of salutary effects on internalizing behaviors, externalizing behaviors, and mental health (Chiswick and Mirtcheva 2013; Petts 2011a, 2011b, 2012; Petts and Knoester 2007; Petts and Kysar-Moon 2012). Longitudinal research is valuable inasmuch as it establishes (1) the causal influence of religiosity on child development, which cannot be determined through cross-sectional inquiries, and (2) the enduring impact of parental religiosity on child development as elementary school students grow older. However, there is still much to be learned about this issue. Our study takes a cue from previous research by exploring the effects of religious homogamy and heterogamy on early child development with respect to the frequency of attendance among married spouses.

At the same time, our investigation augments the current body of scholarship in three distinct ways. First, we examine the extent to which the household religious environment, namely, the frequency of parent-child discussions about religion and the frequency of spousal arguments about religion, may affect the development of young children over time. These factors produced significant effects in a previous cross-sectional study (Bartkowski et al. 2008), but have not been examined longitudinally. Second, we explore a wide range of developmental outcomes, including children's (1) psychological adjustment (e.g., self-control, internalizing problem behaviors); (2) social competence (e.g., interpersonal skills, externalizing problem behaviors); and (3) academic performance (i.e., approaches to learning as well as standardized test scores). The last of these domains is particularly important to examine given scholarly inquiries about religion's potential to undermine educational achievement (Darnell and Sherkat 1997), verbal acumen (Sherkat 2010), and scientific literacy (Sherkat 2011). Third, our study combines subjective assessments of child development (rendered by teachers) with objective measures of developmental outcomes (children's performance on standardized tests). Subjective ratings offered by parents, teachers, or others can be subject to bias, thus underscoring the utility of more objective outcome measures.

\subsection{Religion and Child Development: Prior Research and Theory}

Despite the vast attention paid to structural and cultural predictors of child development (e.g., household income, family composition, race-ethnicity), religion had long been ignored until recently. Significant findings emerged with nationally representative data. Bartkowski et al. (2008) found that parental attendance, and especially high rates of couple attendance, were associated with enhanced self-control, interpersonal skills, and positive learning styles, as well as a diminished incidence of internalizing problem behaviors in children beginning elementary school. These results differed from those observed for older youth (ages 10-17) and young adults (18-23) for whom parents' religious heterogamy did not significantly influence self-esteem or life satisfaction (Petts and Knoester 2007). While findings published in previous research (Bartkowski et al. 2008) were generally more robust for parents' ratings of children's behavior, significant effects also surfaced in teachers' ratings of child development. Moreover, the frequency of parent-child discussions of religion was directly associated with a number of positive parent ratings of children (e.g., self-control, social interaction skills, approaches to learning), though fewer of these findings surfaced in teacher ratings of child development. Likewise, the deleterious effects of spousal conflicts over religion (e.g., diminished self-control, increased emotional problems) were associated with parents' ratings of children but not those of teachers. Bartkowski et al. (2008) were quick to call attention to one significant limitation to their study, namely, the use of cross-sectional data and, hence, their inability to establish causal order in a definitive fashion. They acknowledged that selectivity bias (e.g., the willingness of parents with well-behaved children to attend religious services more frequently) could influence the results in their cross-sectional investigation. 
A group of more recent studies, quite notable for their use of longitudinal data, have corroborated and augmented these findings. A series of investigations conducted by Petts $(2011 b, 2012)$ have demonstrated that religion is a valuable resource for promoting positive child developmental outcomes within households facing social disadvantage (e.g., single-mother-headed families, urban fathers in economically depressed environments). Moreover, salutary effects of parental religiosity have been observed with other nationally representative data, such that families' religious involvement has been shown to facilitate positive psychological health outcomes among children during their preteen and early teenage years (Chiswick and Mirtcheva 2013). This last study corroborated an earlier investigation that revealed protective effects of religion in the intergenerational transmission of depressive symptoms (Miller et al. 1997). ${ }^{1}$

This is not to say that religion produces uniformly positive developmental outcomes for children and youth. For example, spousal arguments about religion often undermine children's psychological adjustment and social competence, even when controlling for other types of spousal arguments (Bartkowski et al. 2008). And internalizing behaviors are more common when (1) children have two parents or a father with strict religious beliefs, and (2) children are raised in single-parent or cohabiting households in which only one parent believes religion is important (Petts 2011a). Moreover, while only marginally significant, the importance of religion among children ages 6-11 is associated with lower levels of psychological health (Chiswick and Mirtcheva 2013). Finally, cross-national data collected from children, including those in the U.S., revealed that household religion fosters greater empathy among children but is also linked with more punitiveness and less altruism (Decety et al. 2015).

Why would religion have such pronounced effects on the development of young children? On the positive side of the ledger, religion has been shown to enhance the parent-child bond for both mothers (Pearce and Axinn 1998) and fathers (Bartkowski and Xu 2000; King 2003; Wilcox 2002). It is not surprising, then, that religion and spirituality are meaningful to many children (see Bartkowski 2007; Holden and Williamson 2014). Moreover, a principal concern of religious communities entails the provision of resources to parents and families (Mahoney 2010; Mahoney et al. 2001, 2003; Wilcox 2008). For this reason, scholars have underscored religion's sanctification of family relationships (Bartkowski et al. 2008; Mahoney 2010; Mahoney et al. 2003) whereby domestic bonds are imbued with special meaning and significance. As Mahoney and colleagues (2003:221) have argued: "Religion is distinctive because it incorporates peoples' perceptions of the 'sacred' into the search for significant goals and values ... [that] deserve veneration and respect ... Indeed, part of the power of religion lies in its ability to infuse spiritual character and significance into a broad range of worldly concerns," including those in the home. Hence, families can use religion as a cultural resource to enhance cohesion, resolve conflicts, and pursue desired goals. In short, religion casts parental responsibilities as covenantal. However, given prior research on the potentially adverse outcomes associated with religiosity (e.g., Bartkowski et al. 2008; Petts 2011a), sanctification must be understood in a contextually specific fashion. Although religion may serve as a bridge in same-faith homes, it can function as a wedge in mixed-faith families. In households in which couples do not share a common faith or argue about religion, children often have poorer developmental outcomes.

This study therefore provides a ripe opportunity to clarify sanctification theory. The process of sanctification would be expected to produce positive outcomes for child development factors that fall squarely within the province of religiosity but not for those that fall outside of religion's sphere of influence. A great deal of research has indicated that major religions, and Christianity in particular, have a central focus on promoting the well-being of families and children (e.g., Bartkowski 2001; Bartkowski et al. 2008; Bartkowski and Grettenberger 2018; Browning and Clairmont 2007; Browning and Miller-McLemore 2009; Wilcox et al. 2004; see Marks and Dollahite 2017 for a comprehensive

1 The effects of religion on child development have also been linked to variations in religiously distinctive child discipline techniques and approaches to nurturing. For example, conservative Protestant parents spank their young children more often, but also hug and praise them more frequently (Ellison et al. 2011; Petts and Kysar-Moon 2012). 
and accessible review). Such research underscores the prevalence of family ministry programs in American congregations. Moreover, the Bible and other religious scriptures focus extensively on fostering healthy marital unions and parent-child relationships (Bartkowski 2001; Browning and Clairmont 2007; Browning and Miller-McLemore 2009). Therefore, it is reasonable to hypothesize that parental religious involvement would influence young children's psychological adjustment and social competence because religions aim to sanctify family relationships and primary attachments that are often viewed as foundational for young children's personal development. By contrast, outcomes that are beyond the purview of family sanctification, such as academic performance, would be expected to be less subject to the influence of religious involvement or perhaps adversely affected by parental religiosity if religious commitment is stressed at the expense of academic mastery. In short, the remarkably robust institutional synergy that marks that religion-family nexus, including widely prevalent congregational family ministry programs, is manifested across denominational traditions (Wilcox et al. 2004). Yet, this same synergy is not evident with respect to the linkages between religion and other social institutions (Bartkowski and Grettenberger 2018). To be sure, religion can influence educational attainment, economic arrangements, and political circumstances, but not with the same principal focus-some might say preoccupation—directed at families. In fact, religion's extensive focus on family and social relationships may detract attention from other considerations. The argument that religious involvement can undermine children's academic performance and educational attainment has been demonstrated in previous research (Darnell and Sherkat 1997; Sherkat 2010, 2011), thereby hinting at the limits and context-specific nature of sanctification. We therefore introduce the theoretical construct of selective sanctification and anticipate differential effects with respect to religion and particular types of child outcomes. Children's psychological adjustment and social development are expected to be enhanced by parental religiosity while their academic performance will not.

Despite the empirical and theoretical insights to emerge from previous research, there are a number of important questions left unanswered that will be addressed by the present investigation. First, while the publication of several longitudinal studies of religion and child development in recent years is quite welcome, the small size of this research literature could benefit from additional scholarship. Augmenting the few longitudinal studies on this topic is necessary to establish with greater confidence the causal influence and enduring impact of religiosity on child development. ${ }^{2}$ Second, very little research has previously examined the extent to which the religious environment within households may affect the development of young children over time. Because religion is best understood as a group property (i.e., a product of social relationships rather than merely an individual attribute), the collective nature of religion clearly needs additional attention. To this end, we examine the longitudinal effects associated with the frequency of parent-child discussions of religion and spousal conflicts over religion. These factors produced significant effects in a previous cross-sectional study (Bartkowski et al. 2008) but have not been examined longitudinally. Finally, our study is able to examine a diverse array of developmental outcomes, including children's psychological adjustment, social competence, and academic performance, thereby complementing subjective ratings of children's behavior with more objective performance measures.

To conduct our study, we use data collected during two different waves of the Early Childhood Longitudinal Study-Kindergarten Cohort (ECLS-K), from baseline (1999) to outcome (2002). Extant research and theory (reviewed above) lead us to generate several hypotheses that are tested in this study. All relationships anticipated in these hypotheses are net of controls, which include child

2 We recognize that debates persist about causation and statistical techniques to account for it. See various articles in Measurement: Interdisciplinary Research E Perspectives 12[4], 2014 and the Bainter and Bollen (2015) rejoinder. We follow convention in child development research by controlling for child characteristics at baseline to prevent time 1 developmental differences from influencing time 2 developmental patterns observed in this study. In this way, our investigation explores the effect of religion on the child development trajectory, that is, changes in child development characteristics from time 1 to time 2. As an additional precaution, all models were also run without time 1 child development characteristics controlled. These results, available from the authors by request, were largely similar. 
development characteristics at baseline, thus providing a more rigorous test of the effects of religious factors. $^{3}$

Hypothesis 1 (H1). More frequent parental religious attendance at baseline will result in (a) more positive psychological and social child development outcomes over time and (b) more negative academic outcomes over time.

Hypothesis 2 (H2). More frequent parent-child discussions of religion at baseline will result in (a) more positive psychological and social child development outcomes over time and (b) more negative academic outcomes over time.

Hypothesis 3 (H3). More frequent spousal conflicts over religion at baseline will result in (a) more negative psychological and social child development outcomes over time and (b) more negative academic performance outcomes over time.

\section{Research Methodology}

\subsection{Data Description}

We use data from the Early Childhood Longitudinal Study-Kindergarten Class of 1998-1999 (ECLS-K) (National Center for Education Statistics (NCES) 2018). The authors conducted the study through secondary data analysis and were not involved in the collection of the data. The ECLS-K is a multisource, multimethod study that focuses on children's early childhood and school experiences beginning with kindergarten. Sponsored by the U.S. Department of Education and National Center for Education Statistics, the initial wave of ECLS-K data was collected from a nationally representative sample of 21,260 kindergarteners and first-graders, as well as their parents and teachers, beginning with the 1998-1999 school year (base year of data collection). The primary sampling units (PSUs) were geographical areas composed of counties or groups of counties, with schools serving as second-stage units sampled within PSUs. Students within schools served as the final unit of the multistage sample design. Our study is limited to couples who were in a marital relationship at the time of the first-grade data collection wave because this characteristic permits us to examine various combinations of religious homogamy and heterogamy, which is essential to testing family sanctification. After listwise deletion, our study sample is 10,720 .

Several waves of data were collected from the full sample following the base year of data collection. Our study uses baseline data from the Spring 1999 (parent-child discussions and spousal arguments about religion) and Spring 2000 (parental worship service attendance) waves of the ECLS-K (first-graders). Child development outcome measures are drawn from the Spring 2002 survey (third-graders), with cross-sectional ratings of children from baseline (Spring 2000) serving as controls. The Spring 2002 survey features a combination of subjective (teacher ratings) and objective (test performance) measures of child development. This multisource data collection strategy permits children's behavioral, emotional, and cognitive development to be assessed.

\subsection{Measures and Analytical Strategies}

Dependent Variables: Child Development Assessments of Teachers and Student Standardized Test Scores. In this study, survey assessments from teachers are used to rate several different child

3 As noted elsewhere (Footnote 2), controlling for baseline child development characteristics is warranted and offers a more stringent model for testing the influence of religious factors. Regrettably, the ECLS dataset measures religion only at baseline. Therefore, changes in parental religiosity since baseline or effects of parental religion prior to baseline cannot be controlled and are a study limitation. 
development outcomes featured in the Spring 2002 wave of the ECLS-K (children's behavioral, emotional, and cognitive development in third grade). The ECLS-K research team created several different scales designed to tap these developmental domains and conducted appropriate statistical tests to ensure the internal reliability of each rating scale. The rating scales featured in the ECLS-K were administered to teachers concerning the child's dispositions, behaviors, and skills in various domains. For each item used to construct the scales described below, teachers in the ECLS-K were asked how often they observed the child exhibit the disposition, behavior, or skill in question. Teacher respondents could choose from among the following response categories (coded as numbered here): (1) never, (2) sometimes, (3) often, and (4) very often. There was also a "no opportunity to observe this behavior" response option (coded as missing data).

For each scale, higher scores indicate teachers' more frequent observation of the characteristic in question. For the self-control scale, teachers were presented with four items that gauged the child's ability to respect the property rights of others, control his/her temper, accept peer ideas for group activities, and respond appropriately to pressure from peers (split-half reliability $=0.79$ ). To gauge the social competence of the child, an interpersonal skills scale was administered to teachers. This scale rated the child's skill in forming and maintaining friendships, getting along with people who are different, comforting or helping other children, expressing feelings, ideas, and opinions in a positive way, and showing sensitivity to the feelings of others (split-half reliability $=0.89$ ). An internalizing behavior problems scale, an indicator of adverse psychological adjustment, inquired about teachers' observation of anxiety, loneliness, low self-esteem, and sadness as exhibited by the child (split-half reliability $=0.76$ ). Teachers also completed an externalizing behavior problems scale. This scale featured five items that measured acting out behaviors, including the frequency at which the child argues, fights, gets angry, acts impulsively, and disturbs ongoing activities (split-half reliability $=0.89$ ). The approaches to learning scale allowed teachers to rate the child's attentiveness, task persistence, eagerness to learn, learning independence, flexibility, and organization (split-half reliability $=0.91$ ). Objective measures of children's school performance were also ascertained. ECLS reports standardized test scores for reading, math, and science. All test items came from the ECLS-K third grade direct cognitive assessment battery. Information on specific test items is limited in ECLS documentation due to copyright restrictions but all tests were administered with fidelity and scores on all tests were comparable across administrations (see National Center for Education Statistics 2018).

\subsection{Key Independent Variables}

Husband's and Wife's Religious Attendance, Couple's Religious Homogamy, and Household Religious Environment. The Spring 1999 and Spring 2000 waves of the ECLS-K provide several religiosity measures. These items include individual measures of parental religiosity (frequency of worship service attendance), which is used to calculate the husband's and wife's attendance, respectively, along with religious attendance homogamy ([dis]parity in father-mother attendance). Parental religiosity is ascertained as an individual measure of the respondent's (typically, mother's) self-reported frequency of attendance at religious services during the past year. The parent respondent also reported his/her spouse/partner's religious attendance during the past year. Response categories for frequency of religious attendance of the husband and wife were coded as numbered: (1) never attend, (2) attend several times a year, (3) attend several times a month, (4) attend once per week, and (5) attend more than once per week.

Because religion is a group property (Bartkowski et al. 2008), religious homogamy for the couple was calculated from the Spring 2000 survey, resulting in six categories: (1) the mother attends more frequently than the father, (2) the father attends more frequently than the mother, (3) both attend sporadically (several times a year), (4) both attend semiregularly (several times a month), (5) both attend frequently (once or more per week), and (6) neither the mother nor the father attend. The first two categories in this recoding scheme are heterogamous, while the last four represent various types of homogamous combinations (frequent, semiregular, sporadic, and no attendance). 
The first five categories were dummy-coded with neither parent attending (category 6) serving as the reference. The operationalization of these concepts is consistent with previously published research (Bartkowski et al. 2008).

Finally, two additional ECLS-K measures on the Spring 1999 parent survey gauge the household religious environment. The first of these items is measured by the question, "How often does someone in your family talk with CHILD about your family's religious beliefs or traditions?" The response options include the following: (1) never, (2) almost never, (3) several times a year, (4) several times a month, and (5) several times a week or more (coded as numbered). The second family religious environment measure taps the couple dimension of the family religious environment by asking, "Do you and your current partner often, sometimes, hardly ever, or never have arguments about religion?" Response categories for this item were coded as numbered to reflect the frequency of couples' arguments about religion, and include (1) never, (2) hardly ever, (3) sometimes, and (4) often. Thus, the household religious environment may be characterized by cohesion or conflict, both of which are accounted for using ECLS data.

\subsection{Control Variables}

Several variables were used as controls in all models to gauge the potentially confounding effects of other social factors: gender and race of the child (with race categorized as white, black, Hispanic, Asian, other race/ethnicity), number of siblings under eighteen years old, family structure (intact family, stepfamily, other family type), family socioeconomic status (family income), region (South, Northeast, Midwest, West), locale (rural-urban), and parents' school involvement. This last indicator is an additive index of parents' involvement in parent-teacher association (PTA) meetings, school events, parent-teacher conferences, open houses, fundraising, and school volunteering. A control for cross-sectional ratings was used for each outcome variable (e.g., teacher ratings of students' self-control in first grade are controlled in longitudinal analyses of self-control), as is gender of the respondent (teacher). The first-grade controls hold constant pre-existing developmental differences, thereby offering the most rigorous assessment of religion's influence on outcomes. Given the large number of dependent and independent variables in this study, the coefficients associated with control variables are not featured in the tables (available upon request). Finally, although parents were surveyed about child discipline, these measures are featured in a separate wave of the survey and thus were not included here.

To conduct this study, multiple linear regression (Ordinary Least Squares) was employed with complex survey design effects controlled. This technique permits an examination of the net effects of the key independent variables (parental religiosity, couples' religious homogamy, and household religious environment) on the dependent variables of interest (child development domains) while holding constant potentially confounding factors. Multiple imputation was performed to maximize the study sample size, and the results were similar prior to and following imputation. Given the large number of statistical controls included in the regression models, adjusted R-squared values were obtained and reported as goodness-of-fit measures.

\section{Results}

Descriptive statistics for all variables before multiple imputation are presented in Table 1. For each variable, the sample size (n) and percent (for categorical variables) or mean and standard deviation (for continuous variables) are presented. Where teacher ratings of child behavior are concerned, means and standard deviations of child outcomes are within expected ranges, and positive characteristics are more commonly observed on average than negative characteristics. Turning to religious predictors, we find that mothers (mean $=2.97$ ) report attending somewhat more frequently than fathers (mean $=2.65$ ) on the five-point attendance scale. Among couples, it is more common for mothers to attend more frequently (19.71 percent of the sample) than for fathers to attend more (2.51 percent). A minority of couples (17.54 percent) are those in which neither partner attends, 
as compared with sporadically attending couples (15.20 percent), semiregularly attending couples (13.06 percent), and frequently attending couples (31.99 percent). Discussions of religion are not uncommon (mean $=3.95)$, and arguments about religion are less common (mean $=1.35$ ), with both measured on a four-point scale.

Table 1. Early Childhood Longitudinal Study (ECLS) 3rd Grade Sample Characteristics before Multiple Imputation.

\begin{tabular}{|c|c|c|c|c|c|c|}
\hline & $\mathbf{n}$ & Percent & Mean & SD & Minimum & Maximum \\
\hline \multicolumn{7}{|l|}{ Dependent variables } \\
\hline Self-control (3rd grade) & 8375 & - & 3.26 & 0.59 & 1.00 & 4.00 \\
\hline Interpersonal skills (3rd grade) & 8360 & - & 3.15 & 0.64 & 1.00 & 4.00 \\
\hline Internalizing problem behaviors (3rd grade) & 8386 & - & 1.59 & 0.52 & 1.00 & 4.00 \\
\hline Externalizing problem behaviors (3rd grade) & 8445 & - & 1.63 & 0.57 & 1.00 & 4.00 \\
\hline Approaches to learning (3rd grade) & 8461 & - & 3.13 & 0.66 & 1.00 & 4.00 \\
\hline Standardized reading test scores (3rd grade) & 10,055 & - & 52.13 & 9.38 & 14.18 & 83.68 \\
\hline Standardized math test scores (3rd grade) & 10,103 & - & 52.04 & 9.54 & 15.95 & 83.86 \\
\hline Standardized science test scores (3rd grade) & 10,090 & - & 52.23 & 9.59 & 20.41 & 82.15 \\
\hline \multicolumn{7}{|l|}{ Religion variables } \\
\hline Father's religious attendance (1st grade) & 10,720 & - & 2.65 & 1.34 & 1.00 & 5.00 \\
\hline Mother's religious attendance (1st grade) & 10,720 & - & 2.97 & 1.30 & 1.00 & 5.00 \\
\hline Neither parent attends (reference) (1st grade) & 1880 & 17.54 & - & - & - & - \\
\hline Mother attends more (1st grade) & 2113 & 19.71 & - & - & 0.00 & 1.00 \\
\hline Father attends more (1st grade) & 269 & 2.51 & - & - & 0.00 & 1.00 \\
\hline Both attend sporadically (1st grade) & 1629 & 15.20 & - & - & 0.00 & 1.00 \\
\hline Both attend semiregularly (1st grade) & 1400 & 13.06 & & & & \\
\hline Both attend frequently (1st grade) & 3429 & 31.99 & - & - & 0.00 & 1.00 \\
\hline Frequency of discussing religion (1st grade) & 10,424 & - & 3.95 & 1.16 & 1.00 & 5.00 \\
\hline $\begin{array}{l}\text { Frequency of arguing about religion (1st } \\
\text { grade) }\end{array}$ & 9848 & - & 1.35 & 0.69 & 1.00 & 4.00 \\
\hline \multicolumn{7}{|l|}{ Control variables } \\
\hline Self-control (1st grade) & 9454 & - & 3.24 & 0.59 & 1.00 & 4.00 \\
\hline Interpersonal skills (1st grade) & 9440 & - & 3.17 & 0.63 & 1.00 & 4.00 \\
\hline Internalizing problem behaviors (1st grade) & 9424 & - & 1.55 & 0.49 & 1.00 & 4.00 \\
\hline Externalizing problem behaviors (1st grade) & 9467 & - & 1.59 & 0.60 & 1.00 & 4.00 \\
\hline Approaches to learning (1st grade) & 9523 & - & 3.12 & 0.68 & 1.00 & 4.00 \\
\hline Child is male (3rd grade) & 5457 & 50.90 & - & - & 0.00 & 1.00 \\
\hline Child is female (reference) (3rd grade) & 5263 & 49.10 & - & - & - & - \\
\hline Child is white (reference) (3rd grade) & 6959 & 64.97 & - & - & - & - \\
\hline Child is black (3rd grade) & 731 & 6.82 & - & - & 0.00 & 1.00 \\
\hline Child is Hispanic (3rd grade) & 1816 & 16.95 & - & - & 0.00 & 1.00 \\
\hline Child is Asian (3rd grade) & 648 & 6.05 & - & - & 0.00 & 1.00 \\
\hline Child is other race/ethnicity (3rd grade) & 558 & 5.21 & - & - & 0.00 & 1.00 \\
\hline Respondent is male (3rd grade) & 729 & 7.29 & - & - & 0.00 & 1.00 \\
\hline Respondent is female (reference) (3rd grade) & 9266 & 92.71 & - & - & - & - \\
\hline Biological parent family (3rd grade) & 8161 & 81.65 & - & - & 0.00 & 1.00 \\
\hline Other family type (reference) (3rd grade) & 1834 & 18.35 & - & - & - & - \\
\hline Number of siblings under age 18 (3rd grade) & 9995 & - & 2.54 & 1.09 & 1.00 & 12.00 \\
\hline Mother age (3rd grade) & 9874 & - & 38.30 & 6.01 & 21.00 & 76.00 \\
\hline Parental education (1st grade) & 10,690 & - & 5.25 & 1.95 & 1.00 & 9.00 \\
\hline Family socioeconomic status (1st grade) & 9995 & - & 0.14 & 0.78 & -2.49 & 2.58 \\
\hline Parental school involvement (3rd grade) & 9987 & - & 4.40 & 1.39 & 0.00 & 6.00 \\
\hline Northeast (3rd grade) & 1957 & 19.07 & - & - & 0.00 & 1.00 \\
\hline Midwest (3rd grade) & 2834 & 27.61 & - & - & 0.00 & 1.00 \\
\hline West (3rd grade) & 2318 & 22.59 & - & - & 0.00 & 1.00 \\
\hline South (reference) (3rd grade) & 3154 & 30.73 & - & - & - & - \\
\hline Rural (3rd grade) & 2343 & 23.31 & - & - & 0.00 & 1.00 \\
\hline Urban (reference) (3rd grade) & 7707 & 76.69 & - & - & - & - \\
\hline
\end{tabular}




\subsection{Children's Psychological and Social Development Outcomes}

Tables 2-6 feature the results of regression analyses using teacher ratings. Unstandardized coefficients and significance levels are reported. In each of these tables, the models are presented such that Model 1 features the net effects (i.e., estimated effects net of control variables) of fathers' religious attendance on the child development outcome in question. Model 2 estimates the net effects of mothers' religious attendance. Model 3 features the estimated net effects of various homogamy combinations (with nonattending couples serving as the reference category). In Models 4 and 5, respectively, the net effects of parent-child religious discussions and spousal arguments about religion are estimated. Model 6 (full model) features the estimated effects of all variables on the particular child development measure in question. (Model 6 cannot include the religious attendance of the mother or father due to its collinearity with homogamy measures.) Recall that Hypotheses 1a, 2a, and 3a refer to parental religious effects on children's psychological adjustment and social competence. These hypotheses are treated first (Tables 2-5).

Turning to the first psychological development outcome, Table 2 reports the coefficients of all predictor variables on teachers' ratings of children's self-control in the classroom. Neither the religious attendance of fathers alone (Model 1) nor mothers alone (Model 2) predicts children's self-control. Among couples' attendance variables (Model 3), significantly greater self-control is exhibited by children whose parents attend semiregularly $(p<0.05)$, when compared with their nonattending counterparts (reference category). Neither parent-child discussions (Model 4) nor spousal arguments about religion (Model 5) have a significant relationship with children's self-control. The sole significant effect observed for this outcome-namely, couples' semiregular attendance-persists in the full model $(p<0.05$, Model 6$)$. Hypothesis 1a, which predicted positive effects from parents' religious attendance, is partially supported. Hypotheses $2 \mathrm{a}$ and $3 \mathrm{a}$, which anticipated a positive outcome associated with parent-child religious discussions and an adverse outcome associated with spousal arguments about religion, were not supported.

Teacher ratings of children's internalizing problem behaviors, another indicator of psychological adjustment, reveal two significant effects (Table 3). In Model 1, fathers' attendance is inversely associated with children's internalizing problem behaviors $(p<0.01)$. Similarly, Model 3 shows that parental semiregular attendance is negatively associated with children's internalizing problem behaviors $(p<0.05)$ but this factor is no longer significant in the full model (Model 6). In addition, mothers' attendance approaches significance $(p<0.10)$. Neither parent-child discussions nor spousal arguments about religion are significant, though the former approaches significance $(p<0.10)$. On this outcome, then, Hypothesis 1a is modestly supported. Hypotheses 2a and 3a are unsupported.

Table 4 presents the coefficients for all predictor variables on teachers' ratings of children's interpersonal skills (social competence). Once again, neither fathers' nor mothers' religious attendance alone affects children's interpersonal skills (Models 1 and 2). Significantly more positive outcomes in social competence are again observed for children whose parents attend semiregularly $(p<0.05)$ when compared with their nonattending peers (reference group) (Model 3). Both parents attending frequently $(p<0.10)$ approaches significance. The frequency of parent-child religious discussions $(p<0.01)$ produces a significant salutary effect on children's interpersonal skills, but couples' religious arguments have no effect (Models 4 and 5). In the full model (Model 6), only parent-child discussions remain statistically significant $(p<0.05)$. Thus, for children's interpersonal skills, Hypothesis $1 \mathrm{a}$ is partially supported, Hypothesis 2a is strongly supported, and Hypothesis $3 a$ is not supported. 
Table 2. Unstandardized coefficients predicting children's self-control (teachers' ratings, $n=10,720)^{a}$.

\begin{tabular}{|c|c|c|c|c|c|c|}
\hline & Model 1 & Model 2 & Model 3 & Model 4 & Model 5 & Model 6 \\
\hline Father's religious attendance & 0.004 & & & & & \\
\hline Mother's religious attendance & & 0.005 & & & & \\
\hline Mother attends more ${ }^{b}$ & & & 0.039 & & & 0.026 \\
\hline Father attends more & & & 0.025 & & & 0.014 \\
\hline Both attend sporadically & & & 0.044 & & & 0.036 \\
\hline Both attend semiregularly & & & $0.078^{* *}$ & & & $0.069 *$ \\
\hline Both attend frequently & & & 0.026 & & & 0.015 \\
\hline Frequency of discussing religion & & & & 0.011 & & 0.008 \\
\hline Frequency of arguing about religion & & & & & 0.019 & 0.017 \\
\hline Adjusted $\mathrm{R}^{2}$ & $20.46 \%$ & $20.47 \%$ & $20.51 \%$ & $20.47 \%$ & $20.45 \%$ & $20.53 \%$ \\
\hline
\end{tabular}

${ }^{a}$ Design effects are corrected with robust standard errors and weights; ${ }^{\mathrm{b}}$ Both do not attend is reference. Covariates included are children's self-control reported by teacher in 1st grade, child's and respondent's gender, child's race/ethnicity, mother's age, parental education, number of siblings $<18$, biological parent family, family SES, region of residence, urban-rural residence, and parental school involvement. Consistent significant control variables: children's self-control reported by teacher in 1st grade (+); child is male (-); child is black (-); child is Asian (+); biological parent family $(+)$; and parental school involvement $(+)$. Note: Parental school involvement is an index variable encompassing parent attendance at (1) PTA meetings, (2) school events, (3) parent-teacher conferences, and (4) open houses; as well as (5) parent participation in fundraising; and (6) parent acting as school volunteer. $+p<0.10$; $^{*} p<0.05$; ${ }^{* *} p<0.01 ;{ }^{* * *} p<0.001$.

Table 3. Unstandardized coefficients predicting children's internalizing problem behaviors (teachers' ratings, $\mathrm{n}=10,720)^{\mathrm{a}}$.

\begin{tabular}{|c|c|c|c|c|c|c|}
\hline & Model 1 & Model 2 & Model 3 & Model 4 & Model 5 & Model 6 \\
\hline Father's religious attendance & $-0.016^{* *}$ & & & & & \\
\hline Mother's religious attendance & & $-0.011+$ & & & & \\
\hline Mother attends more ${ }^{b}$ & & & 0.017 & & & 0.029 \\
\hline Father attends more & & & 0.043 & & & 0.054 \\
\hline Both attend sporadically & & & 0.001 & & & 0.008 \\
\hline Both attend semiregularly & & & $-0.052 *$ & & & -0.042 \\
\hline Both attend frequently & & & -0.035 & & & -0.023 \\
\hline Frequency of discussing religion & & & & $-0.011+$ & & -0.008 \\
\hline Frequency of arguing about religion & & & & & -0.012 & -0.016 \\
\hline Adjusted $\mathrm{R}^{2}$ & $10.22 \%$ & $10.18 \%$ & $10.30 \%$ & $10.17 \%$ & $10.09 \%$ & $10.34 \%$ \\
\hline
\end{tabular}

${ }^{a}$ Design effects are corrected with robust standard errors and weights; ${ }^{b}$ Both do not attend is reference. Covariates included are children's internalizing problem behaviors reported by teacher in 1st grade, child's and respondent's gender, race/ethnicity, mother's age, parental education, number of siblings $<18$, biological parent family, family SES, region of residence, urban-rural residence, and parental school involvement. Consistent significant control variables: children's internalizing problem behaviors reported by teacher in 1st grade $(+)$; child is male $(+)$; child is Hispanic (-); child is Asian (-); biological parent family (-); and parental school involvement (-). Note: Parental school involvement is an index variable encompassing parent attendance at (1) PTA meetings, (2) school events, (3) parent-teacher conferences, and (4) open houses; as well as (5) parent participation in fundraising; and (6) parent acting as school volunteer. $+p<0.10 ; * p<0.05 ; * * 0<0.01 ; * * * p<0.001$ 
Table 4. Unstandardized coefficients predicting children's interpersonal skills (teachers' ratings, $\mathrm{n}=10,720)^{\mathrm{a}}$.

\begin{tabular}{|c|c|c|c|c|c|c|}
\hline & Model 1 & Model 2 & Model 3 & Model 4 & Model 5 & Model 6 \\
\hline Father's religious attendance & 0.011 & & & & & \\
\hline Mother's religious attendance & & 0.008 & & & & \\
\hline Mother attends more ${ }^{b}$ & & & 0.023 & & & 0.003 \\
\hline Father attends more & & & 0.012 & & & -0.004 \\
\hline Both attend sporadically & & & 0.042 & & & 0.026 \\
\hline Both attend semiregularly & & & $0.069 *$ & & & 0.048 \\
\hline Both attend frequently & & & $0.043+$ & & & 0.014 \\
\hline Frequency of discussing religion & & & & $0.022 * *$ & & $0.020 *$ \\
\hline Frequency of arguing about religion & & & & & 0.001 & -0.001 \\
\hline Adjusted $\mathrm{R}^{2}$ & $21.13 \%$ & $21.13 \%$ & $21.18 \%$ & $21.19 \%$ & $21.06 \%$ & $21.24 \%$ \\
\hline
\end{tabular}

${ }^{a}$ Design effects are corrected with robust standard errors and weights; ${ }^{b}$ Both do not attend is reference. Covariates included are children's interpersonal skills reported by teacher in 1st grade, child's and respondent's gender, child's race/ethnicity, mother's age, parental education, number of siblings $<18$, biological parent family, family SES, region of residence, urban-rural residence, and parental school involvement. Consistent significant control variables: interpersonal skills reported by teacher in 1st grade (+); child is male (-); child is Asian (+); biological parent family $(+)$; and parental school involvement (+). Note: Parental school involvement is an index variable encompassing parent attendance at (1) PTA meetings, (2) school events, (3) parent-teacher conferences, and (4) open houses; as well as (5) parent participation in fundraising; and (6) parent acting as school volunteer. $+p<0.10$; $p<0.05$; ** $p<0.01 ;{ }^{* * *} p<0.001$.

Table 5. Unstandardized coefficients predicting children's externalizing problem behaviors (teachers' ratings, $\mathrm{n}=10,720)^{\mathrm{a}}$.

\begin{tabular}{|c|c|c|c|c|c|c|}
\hline & Model 1 & Model 2 & Model 3 & Model 4 & Model 5 & Model 6 \\
\hline Father's religious attendance & 0.002 & & & & & \\
\hline Mother's religious attendance & & 0.002 & & & & \\
\hline Mother attends more ${ }^{b}$ & & & -0.001 & & & -0.002 \\
\hline Father attends more & & & -0.010 & & & -0.003 \\
\hline Both attend sporadically & & & 0.003 & & & 0.009 \\
\hline Both attend semiregularly & & & -0.044 & & & -0.037 \\
\hline Both attend frequently & & & 0.012 & & & 0.021 \\
\hline Frequency of discussing religion & & & & -0.005 & & -0.007 \\
\hline Frequency of arguing about religion & & & & & -0.007 & -0.005 \\
\hline Adjusted $R^{2}$ & $32.10 \%$ & $32.10 \%$ & $32.15 \%$ & $32.10 \%$ & $32.08 \%$ & $32.15 \%$ \\
\hline
\end{tabular}

${ }^{a}$ Design effects are corrected with robust standard errors and weights; ${ }^{b}$ Both do not attend is reference. Covariates included are children's externalizing problem behaviors reported by teacher in 1st grade, child's and respondent's gender, race/ethnicity, mother's age, parental education, number of siblings $<18$, biological parent family, family SES, region of residence, urban-rural residence, and parental school involvement. Consistent significant control variables: children's externalizing problem behaviors reported by teacher in 1st grade $(+)$; child is male $(+)$; child is black (+); child is Asian (-); and biological parent family (-). Note: Parental school involvement is an index variable encompassing parent attendance at (1) PTA meetings, (2) school events, (3) parent-teacher conferences, and (4) open houses; as well as (5) parent participation in fundraising; and (6) parent acting as school volunteer. $+p<0.10$; ${ }^{*} p<0.05 ;{ }^{* *} p<0.01 ; * * * p<0.001$.

No significant effects concerning externalizing problems are observed in Table 5. Hypotheses 1a-3a predicting salutary effects of religious factors are not supported for externalizing problem behaviors. These results were unexpected.

Table 6 displays the regression results for predictor variables on teacher ratings of children's approaches to learning. The effects of parental attendance are again featured in Models 1-3. Fathers' religious attendance $(p<0.05)$ significantly predicts more positive learning dispositions (Model 1 ), as do both semiregular attendance $(p<0.05)$ and frequent attendance among couples $(p<0.05)$ (Model 3$)$. Parent-child discussions of religion and spousal arguments about religion yield no significant effects on children's approaches to learning. Both parents attending frequently is reduced to just below significance $(p<0.10)$ in Model 6 . Therefore, Hypothesis 1a is moderately supported, while Hypotheses $2 \mathrm{a}$ and $3 \mathrm{a}$ are not. 
Table 6. Unstandardized coefficients predicting children's approaches to learning (teachers' ratings, $\mathrm{n}=10,720)^{\mathrm{a}}$.

\begin{tabular}{|c|c|c|c|c|c|c|}
\hline & Model 1 & Model 2 & Model 3 & Model 4 & Model 5 & Model 6 \\
\hline Father's religious attendance & $0.017^{*}$ & & & & & \\
\hline Mother's religious attendance & & 0.011 & & & & \\
\hline Mother attends more ${ }^{b}$ & & & 0.006 & & & 0.001 \\
\hline Father attends more & & & 0.030 & & & 0.026 \\
\hline Both attend sporadically & & & 0.035 & & & 0.031 \\
\hline Both attend semiregularly & & & $0.067 *$ & & & $0.062 *$ \\
\hline Both attend frequently & & & $0.054 *$ & & & $0.048+$ \\
\hline Frequency of discussing religion & & & & 0.009 & & 0.004 \\
\hline Frequency of arguing about religion & & & & & 0.002 & 0.003 \\
\hline Adjusted $\mathrm{R}^{2}$ & $35.25 \%$ & $35.22 \%$ & $35.28 \%$ & $35.18 \%$ & $35.13 \%$ & $35.29 \%$ \\
\hline
\end{tabular}

${ }^{a}$ Design effects are corrected with robust standard errors and weights; ${ }^{b}$ Both do not attend is reference. Covariates included are children's approaches to learning reported by teacher in 1st grade, child's and respondent's gender, child's race/ethnicity, mother's age, parental education, number of siblings $<18$, biological parent family, family SES, region of residence, urban-rural residence, and parental school involvement. Consistent significant control variables: children's approaches to learning reported by teacher in 1st grade (+); child is male (-); child is Asian (+); biological parent family (+); parental education (+); and parental school involvement $(+)$. Note: Parental school involvement is an index variable encompassing parent attendance at (1) PTA meetings, (2) school events, (3) parent-teacher conferences, and (4) open houses; as well as (5) parent participation in fundraising; and (6) parent acting as school volunteer. $+p<0.10 ;{ }^{*} p<0.05 ; * * p<0.01 ; * * * 0.001$.

\subsection{Children's Academic Performance Outcomes}

One contribution of our study entails its analysis of objective measures of children's academic performance. Recall that, consistent with the concept of selective sanctification, Hypotheses $1 \mathrm{~b}-3 \mathrm{~b}$ anticipated adverse outcomes of parental religiosity on children's standardized test performance. The influence of religious factors on this cognitive development domain is featured in Tables 7-9. Table 7 reveals that parental attendance can have an adverse effect on children's reading proficiency when mothers attend more $(p<0.05$, Model 6$)$ and when both parents attend sporadically $(p<0.05$ and $p<0.01$, Models 3 and 6), in support of Hypothesis 1b. Fathers' religious attendance in Model 1 approaches significance in a positive fashion $(p<0.10)$. Interestingly, parent-child discussions about religion significantly bolster children's reading proficiency $(p<0.05$, Models 4 and 6$)$, thus contradicting Hypothesis $2 b$, but are not fully counterintuitive (for reasons explained in the discussion). Hypothesis $3 \mathrm{~b}$ is not supported given the null effects observed for spousal arguments about religion.

Table 7. Unstandardized coefficients predicting children's standardized reading test scores $(n=10,720)^{a}$.

\begin{tabular}{|c|c|c|c|c|c|c|}
\hline & Model 1 & Model 2 & Model 3 & Model 4 & Model 5 & Model 6 \\
\hline Father's religious attendance & $0.155+$ & & & & & \\
\hline Mother's religious attendance & & 0.093 & & & & \\
\hline Mother attends more ${ }^{b}$ & & & -0.504 & & & $-0.846 *$ \\
\hline Father attends more & & & 1.199 & & & 0.911 \\
\hline Both attend sporadically & & & $-0.832 *$ & & & $-1.062 * *$ \\
\hline Both attend semiregularly & & & -0.542 & & & $-0.828+$ \\
\hline Both attend frequently & & & 0.123 & & & -0.240 \\
\hline Frequency of discussing religion & & & & $0.225 *$ & & $0.253 *$ \\
\hline Frequency of arguing about religion & & & & & 0.301 & $0.320+$ \\
\hline Adjusted $R^{2}$ & $25.44 \%$ & $25.41 \%$ & $25.47 \%$ & $25.44 \%$ & $25.41 \%$ & $25.51 \%$ \\
\hline
\end{tabular}

${ }^{a}$ Design effects are corrected with robust standard errors and weights; ${ }^{b}$ Both do not attend is reference. Covariates included are child's and respondent's gender, child's race/ethnicity, mother's age, parental education, number of siblings $<18$, biological parent family, family SES, region of residence, urban-rural residence, and parental school involvement. Consistent significant control variables: child is male (-); child is black (-); child is Hispanic (-); child is other race (-); number of young children (-); biological parent family (+); family SES (+); and parental school involvement (+). Note: Parental school involvement is an index variable encompassing parent attendance at (1) PTA meetings, (2) school events, (3) parent-teacher conferences, and (4) open houses; as well as (5) parent participation in fundraising, and (6) parent acting as school volunteer. $+p<0.10 ;{ }^{*} p<0.05 ;{ }^{* *} p<0.01 ;{ }^{* *} p<0.001$. 
Table 8. Unstandardized coefficients predicting children's standardized math test scores $(n=10,720)^{a}$.

\begin{tabular}{|c|c|c|c|c|c|c|}
\hline & Model 1 & Model 2 & Model 3 & Model 4 & Model 5 & Model 6 \\
\hline Father's religious attendance & -0.063 & & & & & \\
\hline Mother's religious attendance & & $-0.176^{*}$ & & & & \\
\hline Mother attends more ${ }^{b}$ & & & $-1.034 * *$ & & & $-1.143^{* *}$ \\
\hline Father attends more & & & -0.381 & & & -0.472 \\
\hline Both attend sporadically & & & $-0.967 * *$ & & & $-1.043^{* *}$ \\
\hline Both attend semiregularly & & & $-1.089 * *$ & & & -1.186 \\
\hline Both attend frequently & & & $-0.767 *$ & & & -0.890 * \\
\hline Frequency of discussing religion & & & & -0.025 & & 0.086 \\
\hline Frequency of arguing about religion & & & & & 0.046 & 0.082 \\
\hline Adjusted $\mathrm{R}^{2}$ & $22.18 \%$ & $22.19 \%$ & $22.21 \%$ & $22.17 \%$ & $22.17 \%$ & $22.19 \%$ \\
\hline
\end{tabular}

${ }^{a}$ Design effects are corrected with robust standard errors and weights; ${ }^{\mathrm{b}}$ Both do not attend is reference. Covariates included are child's and respondent's gender, child's race/ethnicity, mother's age, parental education, number of siblings $<18$, biological parent family, family SES, region of residence, urban-rural residence, and parental school involvement. Consistent significant control variables: child is male (+); child is black (-); child is Hispanic (-); child is other race; number of young children (-); biological parent family (+); family SES (+); rural residence (-); and parental school involvement $(+)$. Note: Parental school involvement is an index variable encompassing parent attendance at (1) PTA meetings, (2) school events, (3) parent-teacher conferences, and (4) open houses, as well as (5) parent participation in fundraising, and (6) parent acting as school volunteer. $+p<0.10$; $p<0.05$; ${ }^{* *} p<0.01$; ${ }^{* * *} p<$ 0.001 .

Table 9. Unstandardized coefficients predicting children's standardized science test scores $(n=10,720)^{a}$.

\begin{tabular}{|c|c|c|c|c|c|c|}
\hline & Model 1 & Model 2 & Model 3 & Model 4 & Model 5 & Model 6 \\
\hline Father's religious attendance & -0.126 & & & & & \\
\hline Mother's religious attendance & & -0.054 & & & & \\
\hline Mother attends more ${ }^{b}$ & & & -0.330 & & & -0.527 \\
\hline Father attends more & & & -0.508 & & & -0.683 \\
\hline Both attend sporadically & & & $-0.995^{* * *}$ & & & $-1.115^{* * *}$ \\
\hline Both attend semiregularly & & & $-1.251^{* * *}$ & & & $-1.393^{* * *}$ \\
\hline Both attend frequently & & & $-0.549+$ & & & $-0.718 *$ \\
\hline Frequency of discussing religion & & & & 0.042 & & 0.117 \\
\hline $\begin{array}{l}\text { Frequency of arguing about religion } \\
\text { Adjusted } \mathrm{R}^{2}\end{array}$ & $30.52 \%$ & $30.50 \%$ & $30.56 \%$ & $30.49 \%$ & $\begin{array}{l}0.302+ \\
30.51 \%\end{array}$ & $\begin{array}{l}0.299+ \\
30.59 \%\end{array}$ \\
\hline
\end{tabular}

${ }^{a}$ Design effects are corrected with robust standard errors and weights; ${ }^{\mathrm{b}}$ Both do not attend is reference. Covariates included are child's and respondent's gender, child's race/ethnicity, mother's age, parental education, number of siblings $<18$, biological parent family, family SES, region of residence, urban-rural residence, and parental school involvement. Note: Parental school involvement is an index variable encompassing parent attendance at (1) PTA meetings, (2) school events, (3) parent-teacher conferences, and (4) open houses, as well as (5) parent participation in fundraising, and (6) parent acting as school volunteer. $+p<0.10 ;{ }^{*} p<0.05 ;{ }^{* *} p<0.01 ; * * *<0.001$.

As seen in Table 8, children's performance on standardized math tests is adversely predicted by various religious factors, including mothers' attendance $(p<0.05$, Model 2$)$, mothers attending more than fathers $(p<0.01$, Model 3$)$, and couples attending sporadically $(p<0.01)$, semiregularly $(p<0.01)$, or frequently $(p<0.05)$ (Model 3). These generally robust results persist in the full model (Model 6), and are consistent with findings anticipated by Hypothesis $1 \mathrm{~b}$. Parent-child discussions of religion and spousal arguments about religion have no effect on standardized math test scores, thus lending no support to Hypotheses $2 \mathrm{~b}$ and $3 \mathrm{~b}$.

Finally, Table 9 demonstrates that couples' sporadic $(p<0.001$, Models 3 and 6), semiregular $(p$ $<0.001$, Models 3 and 6), and frequent attendance $(p<0.05$, Model 6$)$ are inversely associated with children's performance on standardized science tests, and these effects remain in the full model (Model 6). No effects are observed for parent-child discussions of religion or for spousal arguments about religion, although the latter measure approaches significance in Models 5 and 6. The attendance findings support the expectations of Hypothesis $1 \mathrm{~b}$, with no support observed for Hypotheses $2 \mathrm{~b}$ and $3 b$. Table 10 features a summary of all significant effects observed in the study. 
Table 10. Summary of Observed Results Relative to Hypothesized Effects.

\begin{tabular}{|c|c|c|c|}
\hline $\begin{array}{l}\text { Psychological and } \\
\text { Social Development }\end{array}$ & $\begin{array}{l}\text { H1a: Positive Effect of Parental } \\
\text { Religious Attendance }\end{array}$ & $\begin{array}{l}\text { H2a: Positive Effect of } \\
\text { Religious Discussions }\end{array}$ & $\begin{array}{c}\text { H3a: Negative Effect of } \\
\text { Religious Arguments }\end{array}$ \\
\hline Self-control & $\begin{array}{l}\text { H1a supported for semiregularly } \\
\text { attending couples }\end{array}$ & H2a not supported & H3a not supported \\
\hline $\begin{array}{l}\text { Internalizing behavior } \\
\text { problems }\end{array}$ & $\begin{array}{l}\text { H1a supported for fathers' } \\
\text { attendance and semiregularly } \\
\text { attending couples }\end{array}$ & H2a not supported & H3a not supported \\
\hline Interpersonal skills & $\begin{array}{l}\text { H1a supported for semiregularly } \\
\text { attending couples }\end{array}$ & H2a supported & H3a not supported \\
\hline $\begin{array}{l}\text { Externalizing behavior } \\
\text { problems }\end{array}$ & H1a not supported & H2a not supported & H3a not supported \\
\hline Approaches to learning & $\begin{array}{l}\text { H1a supported for fathers' } \\
\text { attendance as well as } \\
\text { semiregularly and frequently } \\
\text { attending couples }\end{array}$ & H2a not supported & H3a not supported \\
\hline Academic Performance & $\begin{array}{l}\text { H1b: Negative Effect of Parental } \\
\text { Religious Attendance }\end{array}$ & $\begin{array}{l}\text { H2b: Negative Effect of } \\
\text { Religious Discussions }\end{array}$ & $\begin{array}{l}\text { H3b: Negative Effect of } \\
\text { Religious Arguments }\end{array}$ \\
\hline Reading proficiency & $\begin{array}{l}\text { H1b supported; reading } \\
\text { proficiency diminished when } \\
\text { mothers attend more and for } \\
\text { sporadically attending couples }\end{array}$ & $\begin{array}{l}\text { H2b not supported } \\
\text { (opposite effect } \\
\text { observed) }\end{array}$ & H3b not supported \\
\hline Mathematical acumen & $\begin{array}{l}\text { H1b supported; math acumen } \\
\text { diminished by mothers' } \\
\text { attendance, when mothers attend } \\
\text { more, and for sporadically, } \\
\text { semiregularly, and frequently } \\
\text { attending couples }\end{array}$ & $\mathrm{H} 2 \mathrm{~b}$ not supported & H3b not supported \\
\hline Scientific ability & $\begin{array}{l}\text { H1b supported; science ability } \\
\text { diminished for sporadically, } \\
\text { semiregularly, and frequently } \\
\text { attending couples }\end{array}$ & $\mathrm{H} 2 \mathrm{~b}$ not supported & H3b not supported \\
\hline
\end{tabular}

\section{Discussion}

This study set out to examine the longitudinal effects of parental religiosity (individual and couple worship service attendance) and the household religious environment (parent-child religious discussions, spousal conflicts over religion) on child development outcomes among a nationally representative sample of third-graders. The developmental outcomes investigated here ranged widely to include teachers' ratings of children's psychological adjustment (e.g., self-control) and social competence (e.g., interpersonal skills), as well as objective measures of students' performance on standardized tests (reading, math, and science). This broad set of outcome measures was justified by prior research and permitted us to test a refined version of sanctification theory with a construct we called selective sanctification. Given the salutary effects observed for psychological and social development in earlier research, we hypothesized that parental attendance and parent-child discussions about religion would yield protective effects while spousal religious conflicts would undermine child development. However, prior research on religion and educational outcomes led us to be more circumspect on this score. The process of selective sanctification would prioritize the human relationship facets of social life that are central to religion (psychological adjustment and social competence), while downplaying the importance of academic performance (Darnell and Sherkat 1997; Sherkat 2010, 2011). Thus, selective sanctification led us to expect adverse effects (or possibly null effects) of parental and family religiosity with respect to academic achievement as measured through standardized reading, math, and science test performance.

We controlled for baseline child development characteristics to ensure that our study offered a rigorous test of the religious antecedents on child development. We discovered several important 
patterns. Concerning teachers' ratings of children's psychological adjustment and social competence, our expectations about the effects of parental attendance were modestly supported. Select measures of parents' attendance were associated with a number of salutary developmental outcomes in children's classroom behavior, including bolstered self-control and interpersonal skills, fewer internalizing problems, and enhanced approaches to learning. Contrary to previous research (Bartkowski et al. 2008), however, the strongest and most consistent effects were not always observed for children whose parents frequently attend worship services. Desirable effects were observed with greater regularity for children of semiregularly attending couples when compared with their nonattending peers (see Table 10). Moreover, the attendance of fathers was inversely associated with internalizing problem behaviors and positively predicted approaches to learning. By controlling for baseline child characteristics, most of our dependent variables measure developmental gains and losses evident among children over a three-year time period.

There seems to be a threshold attendance effect whereby some worship service attendance produces the greatest gains relative to nonattending families (our reference group). It is possible that children in families who attend very frequently (and have consistently done so) did not reap the same magnitude of developmental gains because frequent attendance early in life already provides children with significant advantages that are not statistically evident when controlling for baseline child characteristics (Bartkowski et al. 2008). Thus, the methodological decision to control for baseline child development characteristics could reduce the observed effects for children of frequently attending couples because developmental gains across waves may be less pronounced for this group of children if they were developmentally "ahead" of their counterparts at the outset. Alternatively, it is possible that attributes not included in this study, such as children's integration in positive peer networks, might be especially influential for those whose parents attend semiregularly because such attendance constitutes an important threshold that fosters a critical form of social inclusion, beyond which there may not be discernible effects. In the end, there is a puzzling U-shaped curve that emerged concerning the positive social effects of semiregular parental attendance when compared with the children of nonattending parents. This unanticipated finding, and the lack of positive social attributes for children of frequently attending parents, needs more investigation. Similarly, fathers' attendance seems to be more instrumental in yielding developmental gains for children than is mothers' attendance. This finding may be linked to women's higher average level of religious involvement when compared with that of men.

For standardized test performance, we observed a number of adverse effects for parental attendance. Clearly, the most negative effects of parental attendance were evidenced in math test performance, but similar findings were observed for reading and science test performance. This pattern is consistent with research that has linked religious factors with suboptimal performance in particular domains of academic achievement and intellectual development (Darnell and Sherkat 1997; Sherkat 2010, 2011). Although our study cannot test for the effects of sectarian denominational affiliation or conservative theological beliefs, this facet of our investigation lends additional credence to the conclusion that parents' attendance is not uniformly positive in children's development. That being said, not all forms of religiosity yield adverse outcomes on academic achievement. More frequent parent-child discussions of religion significantly bolstered standardized test scores for reading, thereby suggesting that such conversations-perhaps practiced as scripture study or religious devotionals within the home-might enhance children's literacy. Also, some forms of parental religiosity (fathers' attendance and both spouses attending semiregularly or frequently) produced salutary effects on children's approaches to learning as rated by teachers. Therefore, children's orientations to learning and their achievement on tests are affected somewhat differently by parental religiosity.

Overall, then, what are we to make of these findings? First, religion remains consequential for the development of third-graders, but does not exert a wholly consistent influence at this stage in children's developmental trajectory. Thus, while religion has been shown to be critical in shaping the developmental foundation of very young children (kindergarteners) (Bartkowski et al. 2008), 
the psychological adjustment, social competence, and academic performance of somewhat older children is likely subject to a mix of religious factors (e.g., parents' attendance) and nonreligious factors (e.g., teachers, peers). If our study is paired with previous research on religion and youth, the profoundly positive influence of religion for very young children (Bartkowski et al. 2008) seems to become more circumscribed by third grade, and then rebounds to yield strongly protective effects during adolescence (Smith and Denton 2005; see also Petts and Knoester 2007).

Second, our study was guided by insights from sanctification theory, which posits that religion creates a strong moral foundation for parenting by casting parent-child relationships as a domain of ultimate concern, that is, a covenantal relationship. It seems that some revision to sanctification theory is in order based on the mixed findings presented here. The empirical process that we have observed is best described as selective sanctification. Parental religiosity yields salutary effects on a number of child development outcomes related to psychological adjustment (e.g., self-control) and social competence (e.g., interpersonal skills). And it can also bolster children's orientations toward learning. However, parental religiosity can also undermine children's academic development in reading, math, and science. In this way, parental religiosity is a mixed blessing in the lives of developing children. Moreover, within the household religious environment, we found that parent-child discussions of religion exhibited generally beneficial effects for developing children with respect to their interpersonal skills and reading scores but that spousal arguments about religion were generally ineffectual (producing null results). Thus, when considering developmental trajectories over time, different facets of the household religious environment yield distinctive effects. In short, this study renders a more complicated portrait concerning the effects of parental and household religion in the lives of young children, such that several salutary outcomes on psychological and social measures are observed alongside a series of mostly adverse effects on academic performance measures. This combination of results is summarized in Table 10. Note that a "positive effect" as described in Table 10 refers to a salutary (that is, a desirable or beneficial) child development outcome. Therefore, more self-control is a positive effect, as are fewer internalizing behavior problems because they are both socially desirable outcomes. A negative effect would be an undesirable outcome. The terms positive and negative in this table do not refer to regression coefficient signs.

Several limitations of our study and promising directions for future research should be kept in mind as work on this important topic proceeds. It should be noted that our study focused on teachers' ratings of children's behavior and actual standardized test performance. Thus, this study was concerned with child development in a particular domain of social life, namely, school. This limitation is important to recognize because religion has been shown to be more influential on children's dispositions and behaviors at home than in school (Bartkowski et al. 2008). So, our findings of inconsistent religious effects at this particular point in the developmental trajectory may be, in part, a product of the school-based outcomes investigated here. They do not rule out the role that religion may play in shaping other facets of children's lives such as relationships with parents and siblings throughout childhood, topics that would certainly benefit from more research.

In addition, it is important to note that the use of a series of separate regression models to conduct these analyses does raise the prospect of a Type I error. A Type I error increases the probability of observing a "false positive," that is, the mistaken discovery of statistically significant effects when the null hypothesis of no significant difference should be accepted. The line of analysis employed in this study was pursued because our investigation extends a previously published article that utilized this methodological approach (Bartkowski et al. 2008). The series of separate regression models was employed in our study with this limitation in mind.

Moreover, the data utilized here did not permit us to investigate denominational differences in child development or parents' theological beliefs (e.g., scriptural inerrancy). Given denominational differences in social outcomes for adolescents (Smith and Denton 2005), this is a noteworthy shortcoming. Until interfaith variations can be investigated (e.g., conservative Protestants versus mainline Protestants versus Catholics), we must be careful not to overstate the conclusions drawn 
here. Finally, long-term developmental trajectories beyond the roughly three-year span between baseline and outcome data analyzed here need additional scrutiny, as does the prospect of religious change among parents. ECLS data only measure religion at baseline, thus leaving possible changes in attendance patterns and the household religious environment unable to be explored.

Setting aside these limitations, the argument for noteworthy forms of religious influence among elementary school-age children-at least in the classroom setting-is supported by this investigation. Religion affects a range of child development outcomes by age eight. And, while its influence on psychological adjustment and social competence is broadly beneficial for young children, its impact on standardized test performance is generally adverse. Religion is an important influence, generally for good and sometimes for ill, as children navigate their way through the grade school years.

Author Contributions: J.P.B. conceived of the study and wrote the majority of this paper, including the key theoretical and empirical arguments, as well as the interpretation of results. X.X. conducted all data analyses and created tables along with contributing to the interpretation of results. S.B. contributed to the literature review of the study.

Funding: This research received no external funding.

Acknowledgments: The authors are grateful for comments offered by colleagues at public presentations of this research.

Conflicts of Interest: The authors declare no conflict of interest.

\section{References}

Bainter, Sierra A., and Kenneth A. Bollen. 2015. Moving Forward in the Debate on Causal Indicators: Rejoinder to Comments. Measurement 13: 63-74. [CrossRef]

Bartkowski, John P. 2001. Remaking the Godly Marriage: Gender Negotiation in Evangelical Families. New Brunswick: Rutgers University Press.

Bartkowski, John P. 2007. Religious Socialization among American Youth. In The Sage Handbook of the Sociology of Religion. Edited by James A. Beckford and N. J. Demerath III. Thousand Oaks: Sage, pp. 511-25. [CrossRef]

Bartkowski, John P., and Susan E. Grettenberger. 2018. The Arc of Faith-Based Initiatives: Religion's Changing Role in Welfare Service Provision. Cham: Springer.

Bartkowski, John P., and Xiaohe Xu. 2000. Distant Patriarchs or Expressive Dads? The Discourse and Practice of Fathering in Conservative Protestant Families. The Sociological Quarterly 41: 465-85. [CrossRef] [PubMed]

Bartkowski, John P., Xiaohe Xu, and Martin L. Levin. 2008. Religion and Child Development: Evidence from the Early Childhood Longitudinal Study. Social Science Research 37: 18-36. [CrossRef]

Browning, Don S., and David A. Clairmont, eds. 2007. American Religions and the Family: How Faith Traditions Cope with Modernization and Democracy. New York: Columbia University Press.

Browning, Don S., and Bonnie J. Miller-McLemore. 2009. Children and Childhood in American Religions. New Brunswick: Rutgers University Press.

Chiswick, Barry R., and Donka M. Mirtcheva. 2013. Religion and Child Health: Religious Affiliation, Importance, and Attendance and Health Status among American Youth. Journal of Family and Economic Issues 34: 120-40. [CrossRef]

Darnell, Alfred, and Darren E. Sherkat. 1997. The Impact of Protestant Fundamentalism on Educational Attainment. American Sociological Review 62: 306-15. [CrossRef]

Decety, Jean, Jason M. Cowell, Kang Lee, Randa Mahasneh, Susan Malcolm-Smith, Bilge Selcuk, and Xinyue Zhou. 2015. The Negative Association between Religiousness and Children's Altruism across the World. Current Biology 25: 2951-55. [CrossRef] [PubMed]

Ellison, Christopher G., Marc A. Musick, and George W. Holden. 2011. Does Conservative Protestantism Moderate the Association between Corporal Punishment and Child Outcomes? Journal of Marriage and Family 5: 946-61. [CrossRef]

Hemming, Peter J., and Nicola Madge. 2011. Researching Children, Youth and Religion: Identity, Complexity, and Agency. Childhood 19: 38-51. [CrossRef] 
Holden, George W., and Paul Alan Williamson. 2014. Religion and Child Well-Being. In Handbook of Child Well-Being. Edited by Asher Ben-Arieh, Ferran Casas, Ivar Frones and Jill E. Korbin. New York: Springer, pp. 1137-69. [CrossRef]

King, Valarie. 2003. The Influence of Religion on Fathers' Relationships with Their Children. Journal of Marriage and Family 65: 382-95. [CrossRef]

Mahoney, Annette. 2010. Religion in the Home, 1999-2009: A Relational Spirituality Perspective. Journal of Marriage and Family 72: 805-27. [CrossRef]

Mahoney, Annette, Kenneth I. Pargament, Nalini Tarakeshwar, and Aaron B. Swank. 2001. Religion in the Home in the 1980s and 90s: Meta-Analyses and Conceptual Analyses of Links between Religion, Marriage, and Parenting. Journal of Family Psychology 15: 559-96. [CrossRef] [PubMed]

Mahoney, Annette, Kenneth I. Pargament, Aaron Murray-Swank, and Nichole Murray-Swank. 2003. Religion and the Sanctification of Family Relationships. Review of Religious Research 44: 220-36. [CrossRef]

Marks, Loren D., and David C. Dollahite. 2017. Religion and Families: An Introduction. New York: Routledge.

Miller, Lisa, Virginia Warner, Priya Wickramaratne, and Myrna Weissman. 1997. Religiosity and Depression: Ten-Year Follow-Up of Depressed Mothers and Offspring. Journal of the American Academy of Child and Adolescent Psychiatry 36: 1416-25. [CrossRef] [PubMed]

National Center for Education Statistics. 2018. Early Childhood Longitudinal Study, Kindergarten Class of 1998-99. Available online: https:/ / nces.ed.gov/ecls/kindergarten.asp (accessed on 1 December 2018).

Nelson, James M. 2009. Psychology, Religion, and Spirituality. New York: Springer, ISBN 978-0-387-87573-6.

Pearce, Lisa D., and William G. Axinn. 1998. The Impact of Family Religious Life on the Quality of Mother-Child Relations. American Sociological Review 63: 810-28. [CrossRef]

Petts, Richard J. 2011a. Parental Religiosity, Religious Homogamy, and Young Children's Well-Being. Sociology of Religion 72: 389-414. [CrossRef]

Petts, Richard J. 2011b. Is Urban Fathers' Religion Important for their Children's Behavior? Review of Religious Research 53: 183-206. [CrossRef]

Petts, Richard J. 2012. Single Mothers' Religious Involvement and Early Childhood Behavior. Journal of Marriage and Family 74: 251-68. [CrossRef]

Petts, Richard J., and Chris Knoester. 2007. Parent's Religious Heterogamy and Children's Well-Being. Journal of the Scientific Study of Religion 46: 373-89. [CrossRef]

Petts, Richard J., and Ashleigh E. Kysar-Moon. 2012. Child Discipline and Conservative Protestantism: Why the Relationship between Corporal Punishment and Child Behavior Problems May Vary by Religious Context. Review of Religious Research 54: 445-68. [CrossRef]

Sherkat, Darren E. 2010. Religion and Verbal Ability. Social Science Research 29: 2-13. [CrossRef]

Sherkat, Darren E. 2011. Religion and Scientific Literacy in the United States. Social Science Quarterly 92: 1134-50. [CrossRef]

Smith, Christian, and Melinda L. Denton. 2005. Soul Searching: The Religious and Spiritual Lives of American Teenagers. New York: Oxford University Press, ISBN-13: 978-0195384772.

Wilcox, W. Bradford. 2002. Religion, Convention, and Paternal Involvement. Journal of Marriage and Family 64: 780-93. [CrossRef]

Wilcox, W. Bradford. 2008. Focused on Their Families: Religion, Parenting, and Child Well-Being. In Authoritative Communities: The Scientific Case for Nurturing the Whole Child. Edited by Kathleen Kovner Kline. New York: Springer, pp. 227-44. [CrossRef]

Wilcox, W. Bradford, Mark Chaves, and David Franz. 2004. Bradford, Mark Chaves, and David Franz 2004. Focused on the Family? Religious Traditions, Family Discourse, and Pastoral Practice. Journal for the Scientific Study of Religion 43: 491-504. [CrossRef]

(C) 2019 by the authors. Licensee MDPI, Basel, Switzerland. This article is an open access article distributed under the terms and conditions of the Creative Commons Attribution (CC BY) license (http://creativecommons.org/licenses/by/4.0/). 